\title{
RESENHA: Sobre a dinâmica relação entre o trabalho e a psique
}

\author{
Anísio José da Silva ARAÚJO ${ }^{1}$ \\ Paulo César ZAMBRONI-DE-SOUZA \\ Universidade Federal da Paraíba, João Pessoa, PB, Brasil
}

Livro: Molinier, P. (2013). O trabalho e a psique: Uma introdução à psicodinâmica do trabalho. Brasilia: Paralelo 15, 343p.

$\mathrm{E}$ m 2013, mais uma obra somou-se ao já expressivo acervo em língua portuguesa (considera-se, além dos livros, artigos e entrevistas) acerca da psicodinâmica do trabalho (PDT): o livro O trabalho e a psique: Uma introdução à psicodinâmica do trabalho, de autoria de Pascale Molinier, publicado pela editora Paralelo 15.

A PDT é uma abordagem que tem conquistado grande difusão no Brasil devido à reflexão e aos conceitos que veicula, e tem contribuído de forma efetiva para dar inteligibilidade a muitos fenômenos que acontecem no mundo do trabalho. A PDT, ao investigar, para além do adoecimento e do sofrimento, o prazer no trabalho, chama atenção para a potência que ele pode ter. Afirma, assim, a centralidade do trabalho na vida psíquica e social, recusando a tese contrária de que o trabalho vem perdendo importância enquanto vetor de integração social.

Reforçando ainda o status que a PDT alcançou no Brasil, pode-se mencionar também a presença constante de Christophe Dejours em eventos acadêmicos (já ocorreram três congressos de psicodinâmica e clínica do trabalho) no país, que inclusive extrapolam o mundo psi e penetram em territórios acadêmicos onde esse tipo de enfoque era pouco usual, como engenharia de produção e administração. Vemos também o mundo jurídico, confrontado com questões para as quais nem sempre encontra-se respostas no patrimônio legal, buscar nas ideias de Christophe Dejours elementos para fundamentar melhor suas decisões acerca dos conflitos no mundo do trabalho.

Pascale Molinier é psicóloga, professora do Conservatoire National des Arts et Métier (Paris), onde integra o Laboratório de Psicologia do Trabalho e da Ação (coordenado por Dejours), e membro do comitê editorial da revista Cabiers du Genre. O texto apresenta, logo de início, um conjunto de autores que esteve na origem da psicopatologia do trabalho (PPT) e sobre os quais ainda temos poucas referências em português. Segundo Molinier, esse seleto grupo de autores procura, partindo de diversas inspirações teóricas, problematizar a saúde mental relacionada ao trabalho, um tema que durante muito tempo foi ignorado pela investigação científica em função da prioridade conferida aos impactos do trabalho no corpo. Ela apresenta a biografia resumida de cada um desses autores, instigando-nos a conhecer mais profundamente as ideias que defendem.

Além disso, em momento de implementação da PEC das domésticas no Brasil, é bem-vinda a parte do livro que se dedica a refletir sobre a condição das trabalhadoras domésticas (em geral mulheres, embora a presença masculina venha crescendo), um tema que está na origem da PPT, especialmente por meio da análise realizada por Louis Le Guillant, do célebre caso das irmãs Papin ${ }^{2}$. Ainda nessa seção, cabe pontuar que, apesar de lançar luz à obra de Le Guillant, o livro acaba por fazer uma crítica que não se sustenta, alegando que sua obra não avançou pelo fato de ele ter ficado limitado à reflexologia pavloviana. No entanto, discordando da autora, podemos afirmar que a leitura atenta da obra de Le Guillant mostra que ele percebeu tais limites

Endereço para correspondência: Universidade Federal da Paraíba, Cidade Universitária Campus I, Castelo Branco, João Pessoa, PB, Brasil 58051970. Telefone: (83) 32167337. Email: anisiojsa@uol.com.br

2 Trata-se da análise realizada por Le Guillant a propósito do duplo assassinato cometido por duas empregadas domésticas, que eram irmãs, contra a patroa e sua filha. 
e buscou superá-los aproximando-se da fenomenologia e utilizando a noção de gestalt social para explicar o ressentimento das irmãs Papin.

A questão da normalidade é tratada com muita propriedade. $\mathrm{O}$ deslocamento da doença em direção à normalidade permitiu à PDT sair da encruzilhada científica em que se viu ao buscar confirmar a tese de que o trabalho no capitalismo era patogênico por natureza. A busca pelos casos de transtornos mentais esbarrou no fato de que os humanos resistem e procuram, por diversos meios, escapar da loucura. Tal empreendimento deixou os pioneiros da PPT de mãos vazias, tendo a sua frente um obstáculo teórico que não projetava nenhum futuro para a disciplina. Esse impasse teórico só encontra uma saída nos anos de 1970, com a retomada, por intermédio de Christophe Dejours, das pesquisas em PPT que, confirmando ser uma via promissora, gerou evoluções que culminaram com a constituição da PDT.

Sem negar o sofrimento e o adoecimento mental no trabalho, a PDT procura deslocar o olhar para a possibilidade de transformação do sofrimento em prazer, uma química favorecida pela dinâmica do reconhecimento cujo efeito principal é o fortalecimento da identidade. Nessa mesma seção, a autora faz referência à obra de Canguilhem, a qual reconhece que a PDT inspirou-se, em parte, para tratar a questão da normalidade. No entanto, ela defende que há uma “(...) ambiguidade do conceito de subjetividade em Canguilhem” (p. 73). Discordamos dessa posição, pois não nos parece que a subjetividade, central para a PDT, estivesse no centro das reflexões do referido autor.

A seguir, o autor dedica-se às noções de trabalho prescrito e real, presta homenagem à ergonomia da atividade, cujos achados teóricos tornaram-se condição para o desvendamento de muitas situações de trabalho não apenas pela PDT, mas também por outras clínicas do trabalho. A noção de real do trabalho, que se traduz nos imprevistos, nos incidentes, nos desfuncionamentos e nas panes, e para os quais não se conta com protocolos estabelecidos, é o terreno propício para o exercício da inventividade dos trabalhadores, momento em que a mobilização subjetiva se apresenta com mais densidade, principalmente porque é do indivíduo e/ou do coletivo de onde devem surgir as saídas pertinentes para as variabilidades no trabalho.

Outras contribuições que podem ser destacadas remetem:

- ao trabalhar, enquanto mobilização do corpo, da inteligência e dos afetos, e que tem o poder de operar um processo mutatório no sujeito e uma (re)criação subjetiva permanente. Para a PDT, o trabalhar possui três poderes principais: o de transformar o mundo, o de objetivar a inteligência e o de transformar o sujeito.

- ao tema da Métis, da inteligência prática e astuciosa, exercida em situação de trabalho e que persegue seus alvos a partir de caminhos mais curtos e econômicos, que atinjam rapidamente o alvo. A métis, nesse sentido, "designa a um só tempo uma forma de inteligência prática (métis) e uma deusa da cosmogonia grega (Métis)" (p. 111), na qual a PDT vai se nutrir para discriminar as propriedades dessa inteligência, cujas características básicas são o engajamento do corpo e seu caráter transgressor.

- à noção de atividade subjetivante, cuja identidade se assenta em quatro atributos: a percepção sensível, pela qual os sentidos operam de forma unificada para sentir o mundo e farejá-lo; a relação com o ambiente, que remete à questão da sintonia e sincronia com o ambiente e de sua "humanização" (p. 125); a troca com o ambiente, ou seja, a "troca simpática com os objetos e as pessoas" (p. 126), o engajamento, o envolvimento e o “colocar-se no lugar de" (p. 126); e o sentir e a experiência, que remetem ao pensamento intuitivo, empático, apoiado na interatividade com o ambiente e que resulta da prática cotidiana do confronto com o que este nos proporciona a cada momento.

- à questão das regras de ofício, sociais - o saber viver, a boa educação, a polidez, a convivialidade, a urbanidade, as relações “compreensíveis e pacificadas" (p. 133) -, técnicas (modos de fazer construídos no tempo por um determinado meio profissional), linguageiras (o jargão profissional, a linguagem de ofício, a condição de intercompreensão) e éticas (“o que é justo fazer e o que não é justo fazer”, p. 140). Tais regras encontram-se na face oculta do trabalho e só se tornam visíveis quando transgredidas ou quando é necessário inventar uma nova regra.

- à questão da identidade, tão atacada em tempos nos quais o assédio moral predomina, trazendo situações nas quais o trabalhador tem de enfrentar as violências da organização do trabalho. Enquanto a personalidade diz respeito aos traços afetivos, cognitivos e morfológicos que permanecem estabilizados durante a vida, a identidade remete “(...) ao lado instável, imprevisível do vir a ser do sujeito” (p.151). Segundo a autora, 
A parte do sujeito que necessita de uma confirmação, retirada a cada dia, sem o que poderá ocorrer uma crise - de identidade - no curso da qual o sujeito não seria mais capaz de reconhecer-se a si próprio, sentindo sua continuidade ameaçada (p.151).

- à questão do reconhecimento no trabalho, tema que a PDT dedica atenção especial pelo poder que carrega de produzir a mutação do sofrimento em prazer e de fortalecer a identidade, protegendo-a do risco de adoecimento psíquico.

- à questão das estratégias coletivas de defesa, descoberta original da PDT. Ao mesmo tempo em que reconhece sua utilidade na proteção da saúde mental, chama atenção para o risco de, quando transformadas em si mesmas, impedirem de "(...) pensar naquilo que provoca sofrimento e que seria importante transformar" (p. 218).

Por último, Pascale dedica parte importante do livro à relação entre PDT e relação social de sexo. Reafirma, assim, a ideia de que o trabalho é sexuado e, por conseguinte, que o sofrimento e o prazer são igualmente marcados por essa condição. As relações sociais de sexo, segundo Daniele Kergoat, remetem a relações hierárquicas entre “(...) o grupo social dos homens e o grupo social das mulheres (...)” (p. 255), que, por sua vez, vivem em constante tensão em torno do trabalho e suas divisões.

Já na parte final do livro, a autora procura discorrer sobre as expressões do processo de adoecimento psíquico na atualidade em decorrência de organizações do trabalho que produzem desconfiança, suspeita, dissolução de coletivos e individualização, cujo resultado é o aumento de casos de lesões por esforços repetitivos (LER/ DORT), depressão, síndrome do esgotamento profissional, suicídio nos locais de trabalho, entre outros. Nesse tópico, entendemos que a reflexão da autora poderia ser ainda mais enriquecida caso fizesse referência (e uma justa homenagem) ao papel da obra de Pierre Marty para o desenvolvimento da PDT no que diz respeito à dimensão psicossomática.

O livro seria ainda mais valioso se alguns capítulos pudessem ter sido mais desenvolvidos, devido à riqueza e à complexidade dos temas abordados. No entanto, o que ele apresenta já permite um excelente ponto de partida para aproximar as questões abordadas, e faz jus ao título do livro: ser uma introdução à PDT. Enfim, constitui mais um recurso para entender a realidade dos mundos do trabalho, discriminando o que pode e o que não pode favorecer a saúde mental. Desse modo, nos instiga a intervir, ainda que no infinitesimal, para que os mundos do trabalho tenham um destino mais favorável, revelando todo o poder transformador que o trabalho pode ter para os indivíduos e para a sociedade. Além disso, essa obra, ao lado de três outros livros de Dejours publicados no Brasil (Dejours, 2012a, 2012b; Lancman \& Sznelwar, 2011), permite ótima aproximação à PDT para os iniciantes e possibilidade de revisão e reflexão para aqueles que já são mais próximos da abordagem.

Os leitores da Revista Psicologia Organizações e Trabalho certamente desfrutarão desse livro. Boa leitura!

\section{REFERÊNCIAS}

Dejours, C. (2012a). Trabalho vivo: Sexualidade e trabalho (Tomo I). Brasília: Paralelo 15.

Dejours, C. (2012b). Trabalho vivo: Trabalho e emancipação (Tomo II). Brasília: Paralelo 15.

Lancman, S., \& Sznelwar, L. (2011). Christophe Dejours: Da psicopatologia à psicodinâmica do trabalho. Rio de Janeiro: Fiocruz, Brasília: Paralelo 15. 